\title{
Higher yields of hybrid rice do not depend on nitrogen fertilization under moderate to high soil fertility conditions
}

\author{
Min Huang ${ }^{1,2^{*}} \mathbb{D}$, Peng Jiang ${ }^{1}$, Shuanglü Shan ${ }^{1}$, Wei Gao ${ }^{1}$, Guohui Ma ${ }^{3}$, Yingbin Zou', Norman Uphoff ${ }^{2}$
} and Longping Yuan ${ }^{3}$

\begin{abstract}
Background: Increasing rice yield with fewer external inputs is critical to ensuring food security, reducing environmental costs, and improving returns. Use of hybrid rice has expanded greatly in China due to its higher yield potential. Meanwhile, large and increasing amounts of nitrogen $(\mathrm{N})$ fertilizers have been used for expanding rice production in China. It is not clear to what extent the success of hybrid rice in China is associated with $\mathrm{N}$ fertilizer inputs.

Findings: We observed that the higher grain yield with $\mathrm{N}$ fertilizer in hybrid rice was driven more by a higher yield without $\mathrm{N}$ fertilizer than by increases in grain yield with $\mathrm{N}$ fertilizer under moderate to high soil fertility conditions.

Conclusions: Our results suggest that greater application of $\mathrm{N}$ fertilizers is not needed to benefit from hybrid rice production under moderate to high soil fertility conditions, and that improving and maintaining soil fertility should be a focus for sustaining hybrid rice production. Moreover, our study also indicates that zero-N testing may be a potentially useful tool to develop hybrid rice with high yield and without requirement of greater external $\mathrm{N}$ inputs under moderate to high soil fertility conditions.
\end{abstract}

Keywords: Grain yield, Hybrid rice, Nitrogen inputs, Sustainable crop production

\section{Findings}

Rice is a staple food for over half of the world's population (Muthayya et al. 2014). Rice yield must increase by at least $1 \%$ annually to meet the growing demand for food that will result from population growth and economic development (Normile 2010). Rice cultivars with higher yield potential are essential to achieve this goal (Peng et al. 2008). Moreover, it is also important to minimize the dependence on external inputs for crop production to reduce adverse environmental impacts, and to get the greatest possible expression of crops' yield potential.

Over the past three decades, the use of large amounts of external inputs such as inorganic fertilizers, especially nitrogen $(\mathrm{N})$, has imposed substantial environmental costs, including increased greenhouse gas emissions

\footnotetext{
* Correspondence: jxhuangmin@163.com; mh2426@cornell.edu ${ }^{1}$ Southern Regional Collaborative Innovation Center for Grain and Oil Crops (CICGO), Hunan Agricultural University, Changsha 410128, China ${ }^{2}$ International Programs-College of Agriculture and Life Sciences (IP-CALS), Cornell University, Ithaca 14853, USA

Full list of author information is available at the end of the article
}

(Davidson 2009), enhanced $\mathrm{N}$ deposition (Liu et al. 2013), soil acidification (Guo et al. 2010), surface water eutrophication (Le et al. 2010), and biodiversity loss (Christopher and Tilman 2008). Diminishing returns are being observed with the use of such fertilizers. In China since the start of its Green Revolution, the ratio of incremental increases in rice production in response to additional applications of $\mathrm{N}$ fertilizer has fallen sharply (Peng et al. 2010).

The development of hybrid cultivars has made a major contribution to increasing the yield potential of rice crops (Yuan 1994). Hybrid rice cultivars have a yield advantage of about $10-20 \%$ over improved inbred rice cultivars (Peng et al. 1999; Cheng et al. 2007). China is the first country to exploit the potentials of hybrid rice commercially on a large scale (Cheng et al. 2004). The area planted under hybrid rice there has expanded greatly since the late 1970s, accounting for more than half of the total national rice-growing area in recent years (Yuan 2014). 
At the same time, fertilizer consumption, especially $\mathrm{N}$, has increased almost linearly in China (Fan et al. 2011). At present, China with approximately $20 \%$ of the world's rice-growing area consumes nearly $40 \%$ of the total $\mathrm{N}$ fertilizer used for rice production (Yan et al. 2006). The average $\mathrm{N}$ application rate for rice production in China is $180 \mathrm{~kg} \mathrm{ha}^{-1}$, about $75 \%$ higher than the world average (Peng et al. 2002; Chen et al. 2014). Moreover, the high yields of hybrid rice cultivars are often achieved when large amounts of resources (including $\mathrm{N}$ fertilizers) are provided, which leads to a perception that hybrid rice cultivars perform better than inbred rice cultivars only under high-input conditions (Yuan et al. 2017). These raise the question of whether the success of hybrid rice in China is related with $\mathrm{N}$ fertilizer inputs. Does the higher yield from hybrid rice depend on $\mathrm{N}$ fertilization?
This is a common concern for farmers who wish to begin planting hybrid rice.

To address the question, two field experiments were conducted during 2012 to 2016 (Additional file 1: Materials and Methods). In each experiment, the treatments included a zero- $\mathrm{N}$ control and two rates of $\mathrm{N}$ fertilization, moderate and high. In one field experiment (Experiment I, 2012-2014), we compared grain yield with $\mathrm{N}$ fertilizer $\left(\mathrm{Y}_{\mathrm{N}}\right)$ with the grain yield obtained without $\mathrm{N}$ fertilizer $\left(\mathrm{Y}_{0}\right)$, also comparing differences between hybrid and inbred rice cultivars in terms of the increases in grain yield attained with $\mathrm{N}$ fertilizer $\left(\Delta \mathrm{Y}_{\mathrm{N}}\right)$. Then, in another field experiment (Experiment II, 2015-2016), we evaluated the trends in $\mathrm{Y}_{\mathrm{N}}, \mathrm{Y}_{0}$ and $\Delta \mathrm{Y}_{\mathrm{N}}$ in representative hybrid rice cultivars selected to represent different phases of hybrid development since 1996.
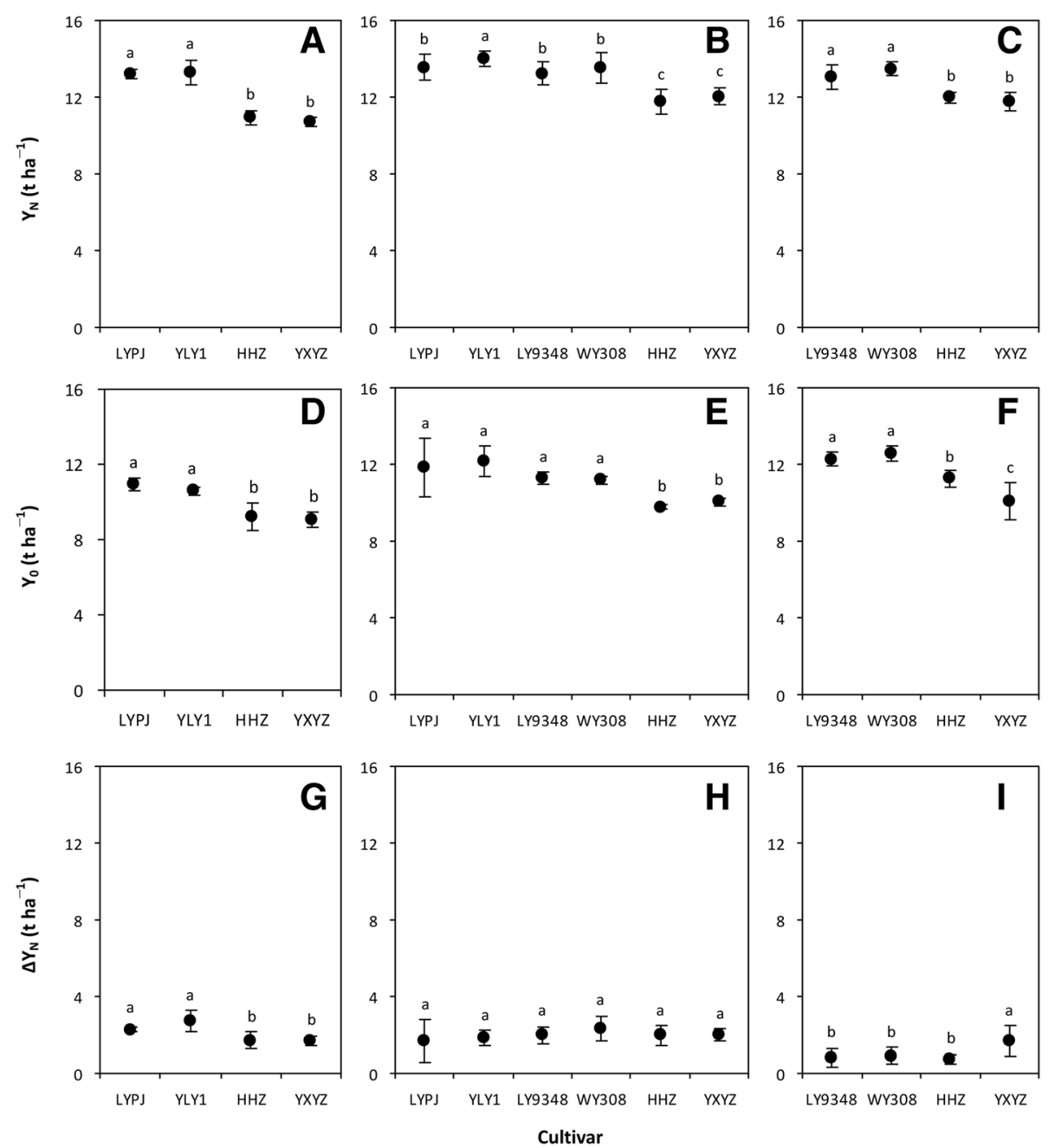

Fig. 1 Grain yield with $N$ fertilizer $\left(Y_{N}, \mathbf{a}-\mathbf{c}\right)$, grain yield without $N$ fertilizer $\left(Y_{0}, \mathbf{d}-\mathbf{f}\right)$, and increase in grain yield with $N$ fertilizer $\left(\Delta Y_{N}, \mathbf{g}-\mathbf{i}\right)$ of hybrid and inbred rice cultivars grown in Xingyi, Guizhou Province, China in 2012 (a, d and g), 2013 (b, e and h) and 2014 (c, f and i). LYPJ (Liangyoupeijiu), YLY1 (Y-liangyou 1), LY9348 (Luoyou 9348) and WY308 (Wuyou 308) are hybrid rice cultivars. HHZ (Huanghuazhan) and YXYZ (Yuxiangyouzhan) are inbred rice cultivars. Data in $\mathbf{a}-\mathbf{c}$ and $\mathbf{g}-\mathbf{i}$ are the means across two $\mathbf{N}$ fertilizer rates. Data points are means and standard deviations of three replications ( $\mathbf{d}-\mathbf{f}$ ) or six replications (a-c and $\mathbf{g}-\mathbf{i})$. Data points marked with the same letters are not significantly different at the 0.05 probability level according to LSD test 


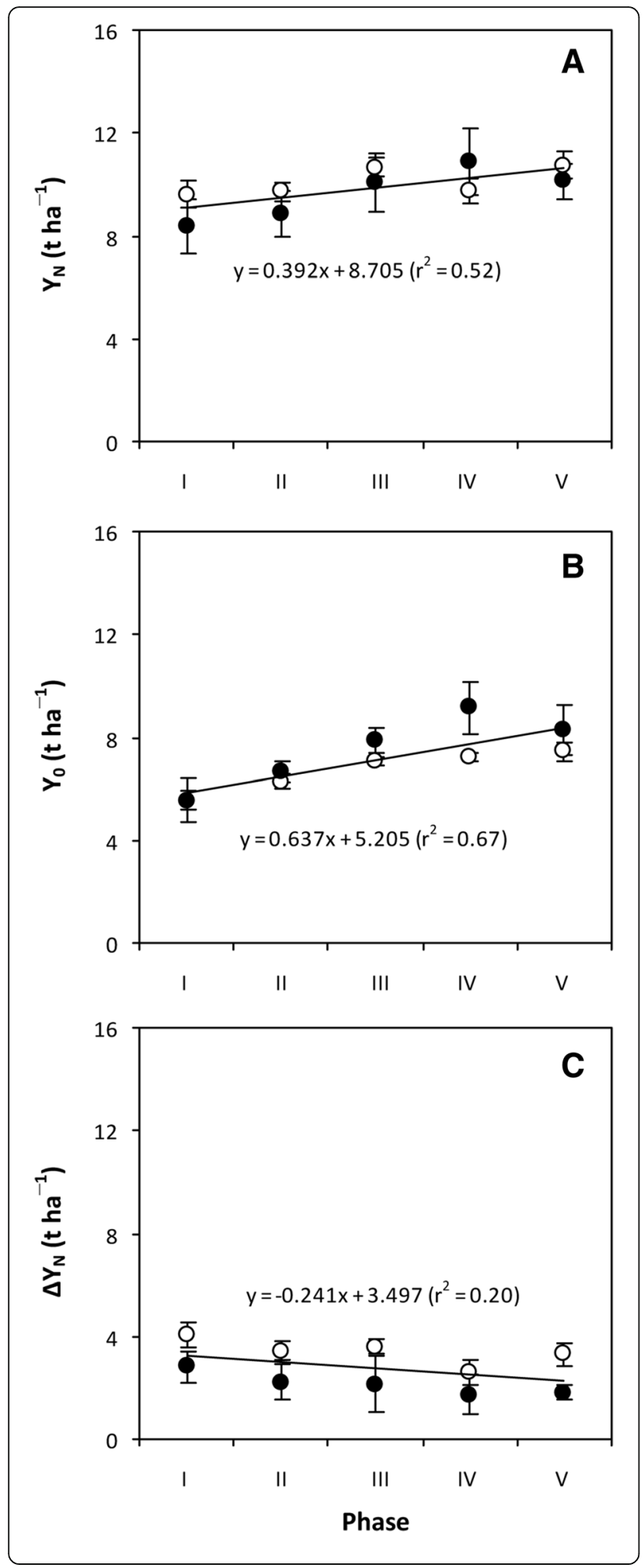

Fig. 2 Trends in grain yield with $N$ fertilizer $\left(Y_{N}, \mathbf{a}\right)$, grain yield without $\mathrm{N}$ fertilizer $\left(\mathrm{Y}_{0}, \mathbf{b}\right)$, and increase in grain yield with $\mathrm{N}$ fertilizer $\left(\Delta \mathrm{Y}_{N}, \mathbf{c}\right)$ of representative hybrid rice cultivars developed during different phases in China since 1996. Phases I, II, III, IV and V are 1996-2000, 2001-2005, 2006-2010, 2011-2015, and 2016-, respectively. Data were obtained from field experiments in which five representative hybrid rice cultivars of the five phases (i.e., Liangyoupeijiu, Y-liangyou 1, Y-liangyou 2, Y-liangyou 900, and Chaoyou 1000) were grown in Ningxiang, Hunan Province, China in 2015 (open circle) and 2016 (closed circle). Data in $\mathbf{a}$ and $\mathbf{c}$ are the means across two $\mathrm{N}$ fertilizer rates. Data points are means and standard deviations of three replications (b) or six replications (a and $\mathbf{c}$ ). Trend (slope) in $\mathbf{c}$ is not statistically significant at the 0.05 probability level according to Student's t test

Because the interaction effect between cultivar and $\mathrm{N}$ rate on grain yield was not significant in all five experiments (Additional file 2: Table S1), in the figures below we report the data on yield and yield increases as means for the two $\mathrm{N}$ fertilizer rates, making interpretation easier.

In the Experiment I, the average $\mathrm{Y}_{\mathrm{N}}$ for the hybrid cultivars Liangyoupeijiu (LYPJ) and Y-liangyou 1 (YLY1) was $22 \%$ and $16 \%$ higher than the $Y_{N}$ for the inbred cultivars Huanghuangzhan (HHZ) and Yuxiangyouzhan (YXYZ) in 2012 and 2013, respectively (Fig. 1a and b). Then in 2013 and 2014, the hybrid cultivars Luoyou 9348 (LY9348) and Wuyou 308 (WY308) had about a $12 \%$ higher average $Y_{N}$ than did the inbred cultivars HHZ and YXYZ (Fig. 1b and c). These magnitudes of yield advantage with hybrid compared to inbred cultivars are similar to those reported in previous studies (Peng et al. 1999; Cheng et al. 2007).

More interestingly, our results showed that the average $\mathrm{Y}_{0}$ from hybrid cultivars LYPJ and YLY1 was $18 \%$ and 21\% higher in 2012 and 2013, respectively, than from inbred cultivars HHZ and YXYZ (Fig. 1d and e). Hybrid cultivars LY9348 and WY308 had 13\% and 16\% higher average $Y_{0}$ than did the inbred cultivars $\mathrm{HHZ}$ and YXYZ in 2013 and 2014, respectively (Fig. 1e and f). However, the difference in $\Delta \mathrm{Y}_{\mathrm{N}}$ between hybrid and inbred cultivars was not consistent or statistically significant (Fig. 1g-i).

These results indicate that the higher $\mathrm{Y}_{\mathrm{N}}$ in hybrid compared with inbred rice cultivars was driven more by their higher $\mathrm{Y}_{0}$ than by $\Delta \mathrm{Y}_{\mathrm{N}}$, which suggests that the higher yield of hybrid rice does not depend on $\mathrm{N}$ fertilization under the experimental soil conditions. This might be attributed to the fact that hybrid rice plants generally have larger, deeper, and more vigorous root systems (Yang and Sun 1986; Zhang et al. 2009), and consequently they are able to absorb more indigenous soil $\mathrm{N}$ than inbred rice plants can.

Consistently, in a micro-plot experiment with application of ${ }^{15} \mathrm{~N}$ labeled urea (Additional file 1: Materials and Methods), we observed that the hybrid rice cultivars LYPJ and YLY1 had significantly more indigenous soil $\mathrm{N}$ uptake, but equal labeled-N uptake, compared to the inbred rice 

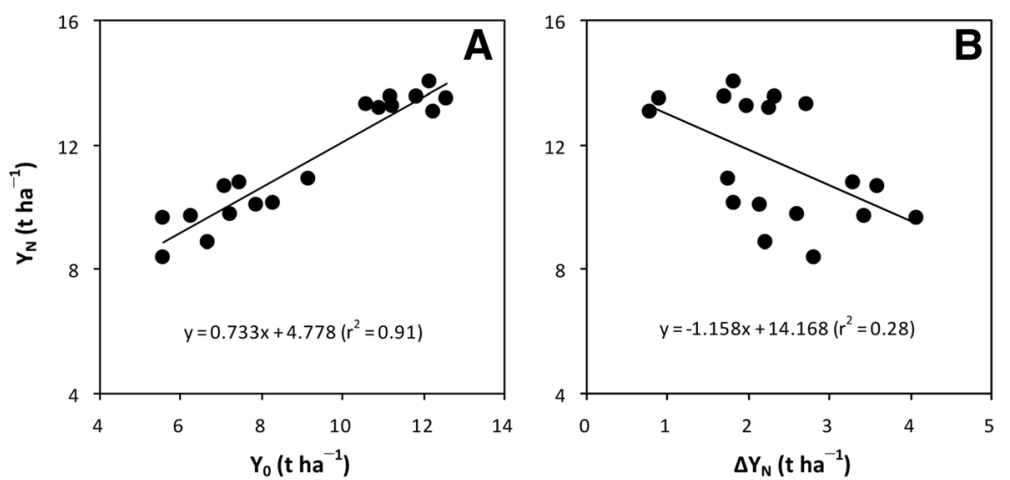

Fig. 3 Relationships of grain yield with $N$ fertilizer $\left(Y_{N}\right)$ to grain yield without $N$ fertilizer $\left(Y_{0}\right.$, a) and increase in grain yield with $N$ fertilizer $\left(\Delta Y_{N}, \mathbf{b}\right)$ in hybrid rice cultivars. Data are a combination of those from hybrid rice cultivars in Figs. 1 and 2

cultivars HHZ and YXYZ (Additional file 3: Table S2). These differences highlight the need for greater fundamental understanding of roots' morphology and physiology in relation to the greater uptake of indigenous soil $\mathrm{N}$ in hybrid rice.

In the Experiment II, both $\mathrm{Y}_{\mathrm{N}}$ and $\mathrm{Y}_{0}$ were significantly increased while no significant trend was observed for $\Delta \mathrm{Y}_{\mathrm{N}}$ in representative hybrid rice cultivars developed during different phases since 1996 (Fig. 2a-c). These results indicate that root system may be improved with the development of new hybrid rice cultivars, and also support the inference that the higher yield of hybrid rice does not depend on $\mathrm{N}$ fertilization.

In addition, our results showed that there was a large difference in $Y_{N}$ in the hybrid rice cultivars LYPJ and YLY1 between the two experiments (Fig. 1a and b; Fig. 2a). The average $Y_{N}$ from LYPJ and YLY1 was $48 \%$ higher in the Experiment I than in the Experiment II. The yield gap in $Y_{N}$ observed between the two experiments was mainly attributable to the difference in $\mathrm{Y}_{0}$ (Fig. 1d and e; Fig. 2b) because the difference in $\Delta \mathrm{Y}_{\mathrm{N}}$ was contrary to that in $\mathrm{Y}_{\mathrm{N}}$ (Fig. 1h and i; Fig. 2c). By combining the data of hybrid rice cultivars in the Experiment I and II, it was observed that $Y_{N}$ was positively correlated with $Y_{0}$ but negatively with $\Delta \mathrm{Y}_{\mathrm{N}}$ (Fig. 3a and b). Such results again support the conclusion that the higher yield of hybrid rice does not depend on $\mathrm{N}$ fertilization.

Because our experiments were conducted under moderate to high soil fertility conditions (Additional file 1: Materials and Methods), the results have implications for the further production and development of hybrid rice under such conditions. First, the higher $\mathrm{Y}_{\mathrm{N}}$ in hybrid rice cultivars was driven more by higher $Y_{0}$ than by $\Delta Y_{N}$, and therefore greater use of $\mathrm{N}$ fertilizers is not needed for more hybrid rice production so much as making improvements in soil fertility should be the focus for sustained hybrid rice production. Second, we note that a super-high $\mathrm{Y}_{\mathrm{N}}$ of more than $13 \mathrm{tha}^{-1}$ was obtained from hybrid rice in the Experiment I (Fig. 1a-c), with about 85\% of such super-high $Y_{N}$ contributed by $Y_{0}$ (Fig. 1d-f). These results indicate that zero- $\mathrm{N}$ testing may be a potentially useful tool to develop super high-yielding hybrid rice without requirement of more external $\mathrm{N}$ inputs.

\section{Additional files}

Additional file 1: Materials and Methods. (DOC 54 kb)

Additional file 2: Table S1.Grain yield in rice cultivars grown under two $\mathrm{N}$ fertilizer rates in Xingyi, Guizhou Province, China in 2012-2014 (Experiment I), and in Ningxiang, Hunan Province, China in 2015 and 2016 (Experiment II). (DOC 53 kb)

Additional file 3: Table S2.Indigenous soil N uptake and labeled-N uptake in rice cultivars in a micro-plot experiment with application of $15 \mathrm{~N}$ labeled urea in Changsha, Hunan Province in China in 2013. (DOC 31 kb)

\section{Abbreviations}

$\Delta \mathrm{Y}_{\mathrm{N}}$ : Increases in grain yield attained with $\mathrm{N}$ fertilizer; HHZ: Rice cultivar Huanghuangzhan; LY9348: Rice cultivar Luoyou 9348; LYPJ: Rice cultivar Liangyoupeijiu; N: Nitrogen; WY308: Rice cultivar Wuyou 308; $Y_{0}$ : Grain yield obtained without N fertilizer; YLY1: Rice cultivar Y-liangyou 1; $Y_{N}$ : Grain yield obtained with N fertilizer; YXYZ: Rice cultivar Yuxiangyouzhan

\section{Acknowledgements}

This work was supported by the Earmarked Fund for China Agriculture Research System (CARS-01). We thank Xuefeng Zhou, Ruichun Zhang, Hengdong Zhang, Jiana Chen and Dandan Wu for joining field experiments.

\section{Authors' contributions}

$\mathrm{MH}, \mathrm{GM}, \mathrm{YZ}$ and LY designed the research. PJ, SS and WG performed the experiments. $\mathrm{MH}$ analyzed the data and wrote the manuscript. NU revised the manuscript. All authors read and approved the final manuscript.

\section{Competing interests}

The authors declare that they have no competing interests.

\section{Publisher's Note}

Springer Nature remains neutral with regard to jurisdictional claims in published maps and institutional affiliations.

\section{Author details}

${ }^{1}$ Southern Regional Collaborative Innovation Center for Grain and Oil Crops (CICGO), Hunan Agricultural University, Changsha 410128, China.

${ }^{2}$ International Programs-College of Agriculture and Life Sciences (IP-CALS), Cornell University, Ithaca 14853, USA. ${ }^{3}$ State Key Laboratory of Hybrid Rice, China National Hybrid Rice Research and Development Center, Changsha 410125, China. 
Received: 27 May 2017 Accepted: 18 September 2017

Published online: 21 September 2017

\section{References}

Chen X, Cui Z, Fan M, Vitousek P, Zhao M, Ma W, Wang Z, Zhang W, Yan X, Yang J, Deng X, Gao Q, Zhang Q, Gui S, Ren J, Li S, Ye Y, Wang Z, Huang J, Tang Q, Sun Y, Peng X, Zhang J, He M, Zhu Y, Xue J, Wang G, Wu L, An N, Wu L, Ma L, Zhang W, Zhang F (2014) Producing more grain with lower environmental costs. Nature 514:486-489

Cheng SH, Cao LY, Yang SH, Zhai HQ (2004) Forty years' development of hybrid rice: China's experience. Rice Sci 11:225-230

Cheng SH, Zhuang JY, Fan YY, Du JH, Cao LY (2007) Progress in research and development on hybrid rice: a super-domesticate in China. Ann Bot 100:959-966

Christopher MC, Tilman D (2008) Loss of plant species after chronic low-level nitrogen deposition to prairie grasslands. Nature 451:712-715

Davidson EA (2009) The contribution of manure and fertilizer nitrogen to atmospheric nitrous oxide since 1860. Nat Geosci 2:659-662

Fan M, Shen J, Yuan L, Jiang R, Chen X, Davies WJ, Zhang F (2011) Improving crop productivity and resource use efficiency to ensure food security and environmental quality in China. J Exp Bot 63:13-24

Guo JH, Liu XJ, Zhang Y, Shen JL, Han WX, Zhang WF, Christie P, Goulding KWT, Vitousek PM, Zhang FS (2010) Significant acidification in major Chinese croplands. Science 327:1008-1010

Le C, Zha Y, Li Y, Sun D, Lu H, Yin B (2010) Eutrophication of lake waters in China: Cost, causes, and control. Environ Manag 45:662-668

Liu X, Zhang Y, Han W, Tang A, Shen J, Cui Z, Vitousek P, Erisman JW, Goulding K, Christie P, Fangmeier A, Zhang F (2013) Enhanced nitrogen deposition over China. Nature 494:459-462

Muthayya S, Sugimoto JD, Montgomery S, Maberly GF (2014) An overview of global rice production, supply, trade, and consumption. Ann N Y Acad Sci 1324:7-14

Normile D (2010) Reinventing rice to feed the world. Science 321:330-333

Peng S, Buresh RJ, Huang J, Zhong X, Zou Y, Yang J, Wang G, Liu Y, Hu R, Tang Q, Cui K, Zhang F, Dobermann A (2010) Improving nitrogen fertilization in rice by site-specific N management: A review. Agron Sustain Dev 30:649-656

Peng S, Cassman KG, Virmani SS, Sheehy J, Khush GS (1999) Yield potential trends of tropical rice since the release of IR8 and the challenge of increasing rice yield potential. Crop Sci 39:1552-1559

Peng S, Huang J, Zhong X, Yang J, Wang G, Zou Y, Zhang F, Zhu Q, Buresh RJ, Witt C (2002) Challenge and opportunity in improving fertilizer-nitrogen use efficiency of irrigated rice in China. Agric Sci China 1:776-785

Peng S, Khush GS, Virk P, Tang Q, Zou Y (2008) Progress in ideotype breeding to increase rice yield potential. Field Crop Res 108:32-38

Yan X, Wu P, Ling H, Xu G, Xu F, Zhang Q (2006) Plant nutriomics in China: An overview. Ann Bot 98:473-482

Yang X, Sun X (1986) Physiological characteristics of hybrid rice roots. In: Hybrid Rice. International Rice Research Institute, Los Baños, p 281

Yuan L (1994) Increasing yield potential in rice by exploitation of heterosis. In: Virmani SS (ed) Hybrid Rice Technology: New Development and Future Prospects. International Rice Research Institute, Los Baños, Philippines, pp 1-6

Yuan $L$ (2014) Development of hybrid rice to ensure food security. Rice Sci 21:1-2

Yuan S, Nie L, Wang F, Huang J, Peng S (2017) Agronomic performance of inbred and hybrid rice cultivars under simplified and reduced-input practices. Field Crops Res 210:129-135

Zhang H, Xue Y, Wang Z, Yang J, Zhang J (2009) Morphological and physiological traits of roots and their relationships with shoot growth in "super" rice. Field Crops Res 113:31-40

\section{Submit your manuscript to a SpringerOpen ${ }^{\circ}$ journal and benefit from:}

- Convenient online submission

- Rigorous peer review

- Open access: articles freely available online

- High visibility within the field

- Retaining the copyright to your article

Submit your next manuscript at $\boldsymbol{\wedge}$ springeropen.com 